\title{
O DESENVOLVIMENTO DA PRIMEIRA INFÂNCIA E O PREPARO PARA O ENSINO PRIMÁRIO
}

\author{
THE DEVELOPMENT OF EARLY CHILDHOOD AND PREPARATION FOR PRI- \\ MARY EDUCATION
}

Adriana do Rosario Pampu ${ }^{1}$, Aldicione Gouveia Junior, Jaqueline Corrêa de Jesus, Maria Eduarda Cavalcante, Rute Dubiella de Lima, Wellen Machado, Dariane Cristina Catapan

\begin{abstract}
RESUMO
O presente artigo tem como intuito trazer as informações a respeito dos objetivos do desenvolvimento sustentável (ODS) que surgiu em 2015 graças ao sucesso dos objetivos de desenvolvimentos do milênio (ODM), que teve inicio em 2000, falando especificamente da meta 4.2 que se refere à qualidade do ensino na primeira infância, que é onde o individuo tem o primeiro contato escolar, e ao preparo de crianças para os anos iniciais do ensino fundamental e como esse preparo é feito,foram utilizados pesquisas bibliográficas, pesquisas de campo e entrevistas com professores e pedagogas de duas instituições de ensino uma publica e outra particular.Os resultados obtidos foram as divergências entre as duas instituições onde a particular executa 0 preparo com foco na alfabetização já a publica respeitam as leis municipais que proíbe a antecipação de conteúdo. Conclui-se que as informações obtidas a respeito da educação nos dias de hoje demonstram que a instituição particular tem um preparo precoce para a pré-alfabetização, já a instituição publica respeitando normas municipais, dá assim um preparo psicológico para o individuo, notou-se que os profissionais de educação em sua maioria não tinham conhecimento sobre os objetivos do desenvolvimento sustentável (ODS), em relação à educação.
\end{abstract}

Palavras-chave: Colégio. Formatação. Regras.

\begin{abstract}
The purpose of this article is to provide information on the objectives of sustainable development (ODS) that emerged in 2015, thanks to the success of the Millennium Development Goals (MDGs), which began in 2000, 4.2 Regarding the quality of early childhood education, which is where the individual has the first school contact, and the preparation of children for the initial years of elementary education, and how this preparation is done, bibliographical research, research field and interviews with teachers and pedagogues of two educational institutions, one public and one private. The results obtained were the divergences between the two institutions where the par- ticular performs the preparation with a focus on the literacy already published it respect the municipal laws that prohibits the anticipation of content. It is concluded that the information obtained regarding education today shows that the private institution has an early preparation for pre-literacy, the institution publishes according to municipal norms, thus provides a psychological preparation for the individual, it was noted that education professionals in their majority were not aware of the objectives of sustainable development (ODS) in relation to education.
\end{abstract}

Keywords: School. Formatting. Rules.

\footnotetext{
${ }^{1}$ Faculdades da Indústria -IEL. E-mail: adriana.pampu@gmail.
} 


\section{INTRODUÇÃO}

A definição para o desenvolvimento sustentável surgiu na Comissão Mundial sobre o Meio Ambiente e Desenvolvimento, que ocorreu em 1987, com o objetivo de harmonizar o desenvolvimento econômico e a conservação ambiental. Quem presidiu essa Comissão foi à médica Gro Harlem Brundtland, mestre em saúde pública e ex Primeira Ministra da Noruega, devido a isso ficou conhecida como Comissão Brundtland. Foi publicado um relatório inovador “'Nosso Futuro Comum', que trouxe o conceito de desenvolvimento sustentável.

Foram oito objetivos de combate à pobreza estabelecida pela Organização das Nações Unidas (ONU), os Objetivos do Desenvolvimento do Milênio (ODM), no ano 2000 juntamente com 191 países, cujo prazo foi até 2015, em 15 anos o progresso foi muito significativo. Os ODM tiveram grande impacto na vida das pessoas, a mortalidade infantil diminuiu consideravelmente, há um número significativo de crianças frequentando as escolas, doenças como a malária e AIDS têm regredido, o acesso à água potável tem sido maior e a pobreza global decrescido. (NAÇÕES UNIDAS, 2018).

Devido ao sucesso dos ODM de conseguirem erradicar a pobreza, mas não por completo, a ONU lançou os Objetivos do Desenvolvimento Sustentável (ODS) em 2015.

São 17 metas cujo principal objetivo é, "não deixar ninguém para trás", essas metas buscam alcançar a dignidade até o ano de 2030. Os 17 planos são, 1 erradicação da pobreza, 2 fome zero e agricultura sustentável, 3 saúde bem-estar, 4 educação de qualidade, 5 igualdade de gênero, 6 água potável e saneamento, 7 energia limpa e acessível, 8 trabalho decente e crescimento econômico, 9 indústria, inovação e infraestrutura, 10 reeducação desigualdades, 11 cidades e comunidades sustentáveis, 12 consumo e produção responsáveis, 13 ação contra a mudança global do clima, 14 vida na água, 15 vida terrestre, 16 paz justiça e instituições eficazes e 17 parcerias e meio de implementação.

Escolhido para o este artigo a meta 4, onde foi abordado o plano 4.2 que trata de garantir que todas as meninas e meninos tenham acesso a um desenvolvimento de qualidade na primeira infância, cuidados e educação pré-escolar, de modo que eles estejam prontos para o ensino primário.

O presente artigo científico tem como objetivo trazer relatos e dados obtidos por pesquisas de campo a respeito do desenvolvimento, verificar, analisar, relatar como a meta 4.2 está 
sendo aplicada em um Centro Municipal de Ensino Infantil (CMEI) e uma instituição particular localizada em São José dos Pinhais.

\section{METODOLOGIA}

Para a realização deste artigo científico no ambiente escolar foram utilizados os seguintes métodos científicos de pesquisa: pesquisa bibliográfica, pesquisa de campo, entrevista.

\subsection{Pesquisa bibliográfica}

Segundo Fonseca (2002) a pesquisa bibliográfica possui a característica do início de um trabalho, onde é realizada a busca de referenciais teóricos que já foram analisados. O objetivo dessa pesquisa é obter a fundamentação teórica sobre o tema abordado, com o intuito de justificá-lo. Para esta pesquisa a equipe utilizou pesquisa em livros, artigos, websites e revistas.

\subsection{Pesquisa de campo}

A pesquisa de campo pode ser utilizada com o objetivo de obter respostas para possíveis problemáticas, podendo desenvolver hipóteses, familiarizar o pesquisador com o ambiente ou clarificar conceitos, dentro da pesquisa de campo existem diversos objetivos. No seguinte trabalho, a pesquisa realizada foi a exploratório-descritiva, que consiste em uma descrição de determinada situação ou fenômeno para um estudo onde serão realizadas análises teóricas ou empíricas, pode-se encontrar descrições quantitativas e/ou qualitativas (MARCONI e LAKATOS, 2003).

\subsection{Entrevista}

A entrevista é uma conversa orientada para um objetivo definido: recolher, por meio do interrogatório do informante, dados para a pesquisa. Recorre-se a entrevista quando não é possível encontrar os dados necessários em fontes documentais (CERVO, BERVIAN e DA SILVA, 2009, p.51). Na pesquisa em campo foi utilizada a entrevista informal, realizada com as pedagogas e outra com as professoras das fases finais da Educação Infantil.

\section{RESULTADOS E DISCUSÃO}


Após realizar as visitas no CMEI e no colégio particular para verificar se a ODS 4.2 está realmente acontecendo foi constatado que a pedagoga do CMEI não tinha conhecimento sobre as ODS, mas foi muito receptiva ao tema, já a pedagoga do colégio particular mostrou conhecimento e interesse sobre o assunto.

Notou-se a divergência entre as duas instituições em relação à pré-alfabetização e ao preparo para ingressar no ensino fundamental I. No CMEI foi observado que os estudantes possuem maior autonomia, onde aprendem a partir de jogos e brincadeiras e no colégio particular o ensino é mais direcionado para a pré-alfabetização.

Segundo Kramer e Abramovay (1995), no artigo “'Alfabetização na pré-escola: exigência ou necessidade'" há um grande debate com relação à pré-escola, um lado acredita que não existe importância na fase pré-escolar, pois o impacto no ensino fundamental é quase irrelevante, e que o investimento financeiro tem que ser muito alto para pouco retorno. Por outro lado, a defesa da pré-escola está relacionada aos que acreditam que ela pode prevenir os problemas do $1^{\circ}$ ano por meio da preparação. Outro grupo defende a pré-escola como formadora global do desenvolvimento da criança sem o caráter preparatório para o $1^{\circ}$ ano. De acordo com as autoras a pré-escola não é inútil, ela tem uma função pedagógica sim que deve valorizar o que a criança conhece, com novos aprendizados, também não é capaz de resolver problemas futuros. A pré-escola tradicional tem sofrido diversas críticas, a corrente inovadora acredita na palavra criatividade, onde a criança não é apenas direcionada a fazer algo, onde são priorizadas as relações interpessoais e a iniciativa da criança, esse discurso inovador nega a validade de se alfabetizar na pré-escola. Na rede privada esse questionamento nunca foi feito, eles continuam a pré-alfabetizar. A mudança de mentalidade está apenas para as classes populares.

De acordo com o Referencial Curricular Nacional para a Educação Infantil (Brasil, 1998) a criança entre quatro e seis anos no eixo de Linguagem Oral e Escrita deve possuir as seguintes habilidades: ampliar gradativamente suas possibilidades de comunicação e expressão, interessando-se por conhecer vários gêneros orais e escritos e participando de diversas situações de intercâmbio social nas quais possa contar suas vivências, ouvir as de outras pessoas, elaborar e responder perguntas; familiarizar-se com a escrita por meio do manuseio de livros, revistas e outros portadores de texto e da vivência de diversas situações nas quais seu uso se faça necessário; escutar textos lidos, apreciando a leitura feita pelo professor; interessar-se por escrever palavras e textos ainda que não de forma convencional; reconhecer seu nome escrito, sabendo identificá-lo nas diversas situações do cotidiano; escolher os livros para ler e apreciar. 
Ainda de acordo com o RCNEI (BRASIL 1998) a criança entre quatro e seis anos no eixo de matemática deve ser capaz de: reconhecer e valorizar os números, as operações numéricas, as contagens orais e as noções espaciais como ferramentas necessárias no seu cotidiano; comunicar ideias matemáticas, hipóteses, processos utilizados e resultados encontrados em situações-problema relativas a quantidades, espaço físico e medida, utilizando a linguagem oral e a linguagem matemática; ter confiança em suas próprias estratégias e na sua capacidade para lidar com situações matemáticas novas, utilizando seus conhecimentos prévios.

Com base nas leis referenciais da educação infantil e visando verificar o andamento do objetivo da ODS 4.2 foram feitas visitas em duas instituições de ensino na cidade de São José dos Pinhais, uma particular e outra pública, durante entrevistas informais com pedagogos e professores obteve as seguintes informações. Para facilitar a compreensão serão separados os depoimentos de acordo com os assuntos abordados.

A instituição particular trabalha com a alfabetização desde o maternal (dois anos), apresentando as vogais, a primeira letra do nome e os números até cinco em especifico, mas a professora avança até dez, pois é importante para a criação da identidade da criança. No "jardim I" (de 3 a 4 anos) é onde é efetivado a escrita e o reconhecimento do nome, como parte da identidade, assim podendo conhecer cada letra, as vogais e o alfabeto, são concretizados nessa idade. Quando a criança chega no "jardim II” (cinco anos), subentende-se que ela conheça o alfabeto (nomeando A, B, C...), só que ainda não conseguem fazer relação com o fonema (imagem com o som que a letra tem), isso só é adquirido conforme o decorrer do ano letivo.

$\mathrm{Na}$ conversa com a pedagoga do CMEI, ela relatou que está previsto pelas diretrizes que não deve haver antecipação de conteúdo. Diz também que mesmo no primeiro ano o eixo continua sendo interações e brincadeiras, e isso deve ser respeitado, pois a ruptura é grande, uma vez que seu aluno que é acostumado com cantinhos, movimentos e brincadeiras se veem diante de uma sala de aula onde deve permanecer sentado registrando as atividades, causando ali certa dificuldade para a criança.

Na instituição particular possui três jardins II, e, por liberação do conselho nacional foi divido as classes por idade das crianças, a primeira turma de jardim II onde as crianças fazem aniversário até março do ano letivo. Na segunda turma de jardim mediana, são os alunos que fazem aniversário entre abril e julho, mais tardar setembro. Nas turmas medianas é respeitado o saber cognitivo da criança, pois terão crianças que conseguiram memorizar as sílabas e entender os fonemas, outras que não, então é incentivado ainda mais a coordenação motora com 
movimentos de pinça, exemplos: rasgar papel, fazer bolinhas que também são trabalhadas na aula de psicomotricidade.

As crianças que fazem aniversário no final de ano são parte da turma $\mathrm{C}$, onde é explicado para todos os pais, de forma clara, que essa turma precisa passar pelo jardim III, porque eles são extremamente imaturos. No jardim III é trabalhado com métodos de ensino diferenciados, foi escolhido outro material para trabalhar a letra cursiva durante todo o ano, não para que a criança escreva tudo em letra cursiva, mas para aprimorar realmente a coordenação e assim desenvolver o raciocino, localização de espaço e a lateralidade. As crianças já estão mais preparadas para o primeiro ano, indo a fundo às sílabas, fonemas e conseguindo montar as primeiras palavras, podendo ir além do que é necessário para o primeiro ano, interpretando textos com mais facilidade.

A idade mínima para ingressar no Ensino Fundamental é de seis anos completos até dia 31 de março, consta pela lei de diretrizes e bases da educação (LDB) e pela Resolução CEB n6/2010. Mesmo com esta leia, ainda existem muitas discussões da criança de cinco anos, que esta fora da idade de corte, se deve ser retida na educação infantil ou não.Devido não existir nenhuma proibição por lei, vários municípios descumpriram a LDB. Por esse motivo em 2017 depois de uma declaração de legitimidade pedida pelo estado do Mato Grosso do sul, o STF deliberou sobre o tema. Com a decisão os estados e municípios que estão com a idade de corte suspensa deveram rever suas regras para se adequar a determinação (SEMIS, 2018).

No CMEI com relação à transição para o ensino fundamental, a pedagoga relatou que em um contato com as professoras de primeiro ano, ouviu considerações de que os alunos chegam lá sem saber pegar no lápis, sem a coordenação motora prevista, e mal compreende as atividades propostas, e logo as professoras de primeiro ano também relataram a ela que são cobradas em relação ao desenvolvimento do aluno. A pedagoga reafirmou que não é respeitado o tempo da criança e que essa ruptura pode trazer até alguns traumas em relação à aprendizagem.

A alfabetização antes do ensino fundamental pode trazer benefícios como o amor pela leitura, mas também pode trazer traumas causados pela pressão involuntária dos pais. De acordo com Piaget a fase pré-operatória, que se inicia após dois anos de idade e segue até os sete anos, onde a criança tem um pensamento egocêntrico, ela pensa de acordo com suas experiências individuais, que torna seus pensamentos carentes de lógica, por isso crianças com idade de até seis anos entendem mal os eventos e tem problemas para expressar. Causando muitas vezes 
traumas como sentimento de inferioridade ou até mesmo desistir antes de tentar. (PIAGET e INHELDER, 2002).

A Pedagoga afirmou também que a transição é feita com passos bem lentos, anualmente são feitas reuniões entre professoras, pedagogas e diretoras com objetivo de conversar e discutir sobre essa transição. Depois disso, é realizada uma visita na escola municipal mais próxima onde à maioria das crianças são encaminhadas para o primeiro ano, e lá as professoras preparam atividades e há todo um momento para que haja interação com as crianças da préescola. Da mesma forma é feito no CMEI, onde também é tudo preparado para que as professoras de primeiro ano conheçam melhor como acontece o trabalho dentro do mesmo. Porém no último ano, nenhuma das professoras que fizeram esse momento de transição continuou como responsável pelo primeiro ano, ou seja, houve um retrocesso e com isso a dificuldade da transição permaneceu.

A professora do CMEI iniciou a fala relatando que existe no município um projeto de transição, onde há trocas de experiências entre professoras do pré e professoras do primeiro ano. Segundo o portal da prefeitura de São José dos Pinhais

\footnotetext{
"O objetivo é de proporcionar uma transição adequada a essas crianças tão pequenas que a Secretaria Municipal de Educação, por meio dos Departamentos de Educação Infantil e de Ensino Fundamental, desenvolve o projeto de Transição CMEI-Escola, através de assessoramento e da parceria entres as unidades próximas entre si." (SECRETÁRIA DE EDUCAÇÃO, 2015)
}

A professora do CMEI afirmou, que a preparação dos alunos que passaram por essa transição é através de atividades e brincadeiras de linguagem corporal e também através de atividades específicas, como por exemplo: rasgar e amassar diversos tipos de papéis, manuseio de tesoura e massinhas de modelar, entre outras.

A professora docolégio particular relata que a educação infantil e o ensino fundamental são etapas completamente diferentes, com objetivos específicos e rotinas próprias. A educação infantil favorece interações mais plurais, com maior espaço tanto para a questão lúdica quanto para o diálogo. Já no ensino fundamental, a estrutura organizacional privilegia práticas individuais e baseia-se na transmissão dos conteúdos. A princípio esta pode parecer uma mudança simples, mas se levarmos em consideração as diferenças entre os dois segmentos vamos perceber que modifica muito a rotina da criança. Essa transição, como qualquer outra, requer atenção e cuidado por parte de pais e educadores. Além das questões específicas que envolvem o novo 
segmento a criança precisará se adaptar aos novos amigos, nova professora e a um novo ambiente. Como o colégio oferece os dois segmentos (educação infantil e ensino fundamental) essa transição acontece de forma mais tranquila. Essa transição, como qualquer outra, requer atenção e cuidado por parte de pais e educadores. Além das questões específicas que envolvem o novo segmento a criança precisará se adaptar aos novos amigos, nova professora e a um novo ambiente. Como o colégio oferece os dois segmentos (educação infantil e ensino fundamental) essa transição acontece de forma mais tranquila.

A avaliação na instituição particular é feita por parecer descritivo, tabelado com os conteúdos, aspectos sociais, cognitivo, oral, escritas e matemática. A professora estabelece os níveis, se a criança alcançou os objetivos, se está em processo, se não alcançou e se aquele item não foi trabalhado, no final do parecer (contracapa), é feito um breve relato de um parágrafo de como está à criança naquele momento e o que ela espera para a próxima etapa.

De acordo com Freud(1920), o período de latência tem início aos cinco anos, aproximadamente, e prolonga-se até ao início da puberdade. É uma fase relativamente tranquila porque as fantasias e impulsos de ordem sexual são substituídos pelo desenvolvimento cognitivo e pela absorção de normas e valores sociais.

Já a avaliação no CMEI no ano em que antecede o primeiro ano do fundamental é feita por meio de reconhecimentos do próprio nome, se o educando consegue nomear seus pertences e se há o reconhecimento do nome dos outros colegas, se já identifica as cores e números, porém nada forçado tudo por meio de interações e brincadeiras. Ao final do ano, as professoras da préescola fazem um parecer que contém todas as atividades realizadas pelo aluno, conteúdos trabalhados e desenvolvimentos obtidos. Os professores do estudante deverão entregar os documentos para a nova instituição de ensino fundamental onde for encaminhado, e assim as professoras de primeiro ano já terão uma base para conhecer seu novo aluno.

A professora do colégio particular também relatou que diferente do ensino fundamental, na educação infantil é realizada uma avaliação continua tendo um olhar diferenciado para cada aluno, mas sempre ao termino de cada semestre também é realizado um relatório descritivo, pontuando os desenvolvimentos e as suas dificuldades.Na educação infantil também é colocado ênfase na coordenação motora, sendo trabalhado com atividades diferenciadas diariamente.

A professora do CMEI relatou que é usado o parecer descritivo para realizar a avaliaçãona educação infantil, onde a criança é observada durante o semestre e o professor registra 
as informações mais relevantes. Afirmou também que a maioria das crianças passa para o primeiro ano já reconhecendo cores e números tudo através de jogos e brincadeiras e também atividades de registro e conteúdos sistematizados.

De acordo com Mansani (2018) avaliar na educação infantil é muito complexo, pois exige uma boa formação docente, pois a maior dificuldade é compreender a criança como sujeito histórico e social, pois o professor deve focar no desenvolvimento da criança e há diferentes maneiras de avaliar esse processo não somente com a ficha/parecer descritivo, mas também com o portfólio, que é composto por fotos, fichas, documentos e vários elementos que podem facilitar essa avaliação.

Por fim a pedagoga do CMEI enfatizou a valorização da infância, a autonomia e o lúdico como forma de aprendizagem.

\footnotetext{
Alguns alunos estão imersos nesse contexto, convivendo com adultos alfabetizados e com livros em casa e aprendendo as letras no teclado do computador. Eles fazem parte de um mundo letrado, de um ambiente alfabetizador. Outros não: há os que vivem na zona rural, onde a escrita não é tão presente, e os que, mesmo morando em centros urbanos, não têm contato com pessoas alfabetizadas e com os usos sociais da leitura e da escrita. (SCARPA, 2006)
}

É notório que nas primeiras fases da educação, ou seja, educação infantil, que a criança experimenta o mundo fora do núcleo familiar, nos dias de hoje essa fase da vida não é mais um lugar onde a criança é apenas cuidada, hoje em dia é nessa fase onde ela aprende a conviver e cria os primeiros laços de amizade. É neste momento em que são construídos os alicerces da personalidade e conhecimentos. Na educação infantil as crianças aprendem de forma passiva, brincando com os sons das palavras e manuseando livros, revistas, gibis, etc. Nesta fase o professor lê para a turma e serve como escriba escrevendo o que elas pedem.

A professora do colégio particular aindapontua que a relação ao requisito escola e família muita das vezes não está totalmente ligada a parte pedagógica, pois muitos pais ainda não valorizam a importância do aprendizado na educação infantil, levando em consideração o cuidar. Com isso a escola está tendo um trabalho dobrado para mudar essa visão.

Por fim a sobre a relação família e escola, comentou que a maioria das famílias que a professora do CMEI tem contato demonstram preocupação e ansiedade quanto à aprendizagem do seu filho, e os estimulam e os incentivam em casa. 


\section{CONCLUSÃO}

Conclui-se que as escolas visitadas atendem crianças de diferentes classes sociais, onde os trabalhos desenvolvidos são divergentes, uma por exigir resultados se esquecendo de que antes de estudante aquele individuo é uma criança e como tal necessita incluir o brincar com propósito e livre também em sua rotina. Por outro lado notamos uma instituição que preza tanto apenas o brincar sem propósito que por fim não proporciona o preparo necessário à criança para os próximos anos, deixando de estimular suas habilidades. Sendo assim observa-se que nenhuma das instituições pesquisadas conseguem atingir o ODS 4.2.

Para a realização deste artigo houveram algumas limitações como, alguns acadêmicos da equipe não puderam comparecer as visitas desenvolvidas nas escolas, e a falta de disponibilidade da escola para visitação, para a aplicação das atividades diagnosticas. Desde a primeira visita os acadêmicos foram bem recepcionados pelos funcionários das instituições.

Para futuras pesquisas acadêmicas a equipe sugere uma pesquisa ampla sobre os conhecimentos que os alunos adquiriram nessa fase por meio de uma avaliação diagnostica, e como estão se desenvolvendo nas primeiras fases do ensino fundamental.

\section{REFERÊNCIAS}

17 OBJETIVOS PARA TRANSFORMAR NOSSO MUNDO. NAÇÕES UNIDAS. Disponível em <https://nacoesunidas.org/pos2015/>. Acesso em 26 de agosto de 2018.

BRASIL. Ministério da Educação e do Desporto. Secretaria de Educação Fundamental. Referencial Curricular Nacional para a Educação Infantil/ Ministério da Educação e do Desporto, Secretaria da Educação Fundamental Brasília: MEC/SEF, 1998. 3v: il.

CERVO, A.; BERVIAN, P.; DA SILVA, R. Metodologia Científica. São Paulo: Pearson Prentice Hall, 2009.

FONSECA, J. Metodologia da pesquisa científica. Fortaleza: UEC, 2002. Apostila

FREUD,S. Além do principio de prazer, L\&PM Pocket. Berlin Alemanha. publicado,1920.

KRAMER, S. ABRAMOVAY.M. Alfabetização na pré-escola: exigência ou necessidade; São Paulo,1995.

LUCKESI, C.C; Avaliação da aprendizagem escolar; 21. ed.- São Paulo: Cortez, 2010 
MANSANI, M. Como avaliar na educação infantil?; disponível em: https://novaescola.org.br/conteudo/11906/blog-de-alfabetização-como-avaliar-na-educacao-infantil. Acesso em 27/09/2018

MARCONI, M.; LAKATOS, E.M. Fundamentos da metodologia científica. São Paulo: Atlas, 2003.

PIAGET, J; INHELDER, B. A psicologia da criança; Bertrand Brasil. Ltda. 18. Ed. - Rio de Janeiro - RJ 2002.

SCARPA, R. Alfabetizar na Educação Infantil, Pode?;2006.disponível em <https://novaescola.org.br/conteudo/126/alfabetizar-na-educacao-infantil-pode>; acesso 24/09/2018.

SECRETARIA DA EDUCAÇÃO. Secretaria de educação tem projeto de transição CMEI- Escola. São José dos Pinhais, 2015. Disponível em<http://www.sjp.pr.gov.br/secretaria-de-educação-tem-projeto-de-transicao-cmei-escola/; acesso: 30/09/2018.

SEMIS, L. Veja o que mudou na idade mínima para ingresso no infantil e Fundamental; disponível em < https://novaescola.org.br/conteudo/12222/veja-o-que-mudou-ou-nao-naidade-minima-para-ingresso-na-educacao-infantil-e-fundamental>; acesso 27/09/2018.

WWF.O QUE É O DESENVOLVIMENTO SUSTENTÁVEL?.. Disponível em https://www.wwf.org.br/natureza_brasileira/questoes_ambientais/desenvolvimento_sustentavel/. Acesso em 26 de agosto de 2018. 